\title{
O ARQUIVO DA AGÊNCIA PORTUGUESA DO AMBIENTE: CONTRIBUTOS GEOGRÁFICOS PARA O ESTUDO DOS RIOS DO NORTE DE PORTUGAL
}

The Portuguese Environment Agency archive: geographical contributions to the study of north portugal rivers

El archivo de la Agencia de Medio Ambiente Portugués: contribuciones geográficas al estudio de los ríos portugales del norte

*Professor auxiliar, Departamento de Geografia e Centro de Estudos em Geografia e Ordenamento do Território (CEGOT), Universidade do Minho - costafs@geografia.uminho.pt.

** Professor auxiliar, Departamento de Geografia e Centro de Estudos em Geografia e Ordenamento do Território (CEGOT), Universidade do Minho - vieira@geografia.uminho.pt.

Recebido em 20/10/2019. Aceito para publicação em 20/10/2019.

Versão online publicada em 10/11/2019 (http://seer.ufrgs.br/paraonde)

\section{Resumo:}

A Agência Portuguesa do Ambiente (APA) é a entidade possuidora de um valioso arquivo resultante da atividade centenária desenvolvida pelos Serviços Hidráulicos com tutela sobre a gestão da água e o planeamento dos recursos hídricos. Os processes arquivados no acervo da APA contam casos de estudo que percorrem os usos das águas públicas para diferentes fins, as modalidades da sua utilização, nas técnicas mais tradicionais, e a sua inserção nos diferentes processos produtivos industriais. Este artigo apresenta algumas temáticas de interesse geográfico relacionados com as bacias do norte de Portugal e à evolução das características morfométricas de seus cursos de água.

Palavras-chave: Fontes, bacias hidrográficas, hidrologia, usos.

\begin{abstract}
:
The Portuguese Environment Agency is the entity that owns a valuable archiveresultingfromthecentenaryactivitycarried out bytheHydraulicServicesresponsible for water management andwaterresourcesplanning. The processes filed in the APA collectioncontain case studiesthat cover the use ofpublicwaters for differentpurposes, themodalitiesoftheir use in themosttraditionaltechniques, andtheirinsertion in thedifferent industrial production processes. Thisarticlepresents some themesofgeographicalinterestrelated to the basins ofnorthern Portugal andtheevolutionofthemorphometriccharacteristicsoftheirwatercourses..
\end{abstract}

Key-words:Sources, publicwaters, hydrology, uses.

\section{Resumen:}

La Agencia Portuguesa de Medio Ambientees la entidadpropietaria de un valioso archivo resultante de la actividadcentenariallevada a cabo por los Servicios Hidráulicos responsables de la gestióndel agua y la planificación de los recursos hídricos. Los procesosarchivadosenel archivocontienenestudios de casos que cubren el uso de aguas públicas para diferentes propósitos, las modalidades de su uso en las técnicas más tradicionales y suinserciónen los diferentes procesos de producción industrial. Este artículo presenta algunos temas de interés 
geográfico relacionados con las cuencasdel norte de Portugal y la evolución de las características morfométricas de sus cursos de agua.

Palabras-clave:Fuentes, cuencashidrográficas, hidrología, usos.

\section{Introdução}

São várias as formas de abordagens documentais utilizadas para ter-se acesso ao contexto histórico de determinado período estudado. As fontes primárias escritas são testemunhas do passado, "pegadas" deixadas na história pela ação dos homens, que o investigador utiliza para reconstruir a memória o mais próximo possível do que aconteceu (CARVALHO, 2009;COSTA et al., 2017; KETELAAR, 2004; MILLIGAN 1979). Documentos jurídicos, sentenças, correspondência, inventários, censos, mapas, gráficos etc. são as algumas das diversas interpretações que os pesquisadores realizam das fontes primárias que podemos encontrar em arquivos e departamentos vinculados aos órgãos públicos que mantenham a prática do arquivamento de documentos (COSTA et al., 2017; PRADO, 2010).

A Agência Portuguesa do Ambiente (APA) é a entidade possuidora de um valioso arquivo resultante da atividade centenária desenvolvida pelos Serviços Hidráulicos $(\mathrm{SH})$ com tutela sobre a gestão da água e o planeamento dos recursos hídricos. Desde o Minho ao Douro, passando pelo Lima, Cávado, seus afluentes mais importantes e outros cursos de água, que marcam o mapa hídrico do Norte de Portugal, confrontamo-nos com a arte dos engenheiros e desenhadores, nos projetos promovidos pelas Hidráulicas; com os pedidos e queixas de cidadãos, com a avaliação dos projetos propostos por particulares; com as histórias dos guarda-rios e com os relatos pormenorizados do escrivão recolhido em seu ofício; tudo isso através de mapas, projetos, ofícios, cadastros, relatórios, notações de correspondência (CAMPELO, 2011; COSTA, 2012, 2011, 2010; COSTA e CORDEIRO, 2012, 2012A, 2015, 2015a; COSTA et al.,2015).

Os processes arquivados no acervo da APA contam casos de estudo que percorrem os usos das águas públicas para diferentes fins, as modalidades da sua utilização, nas técnicas mais tradicionais associadas à rega e a sua inserção nos diferentes processos produtivos industriais, realçando a importância da hidroeletricidade, sem esquecer os usos públicos e a ocupação das margens para outras atividades (COSTA, 2012; COSTA et al., 2015). São assim várias as áreas temáticas de interesse geográfico na análise destes processos, bem como os problemas, impactes e condicionantes das atividades humanas para a gestão do Domínio Público Hídrico (DPH). De entre os milhares de pastas existentes no arquivo, encontram-se os processos relacionados com o DPH que consultamos e analisamos, desde 1886 até à atualidade, e que demonstram a relevância das fontes geográficas para a produção de informação no conhecimento dos cursos de água e áreas ribeirinhas dessa região (COSTA et al., 2017).

As regiões hidrográficas que compreendem as áreas de estudo - Minho e Lima, Cávado, Ave e Leça e Douro estão representadas na figura 1.

ParaOnde!?, Porto Alegre, v.12 n.2, p.238-251, 2019.http://seer.ufrgs.br/paraonde Edição Especial - III Colóquio de Pesquisadores em Geografia Física Ensino de Geografia 
Figura 1 - Localização das bacias do norte de Portugal.

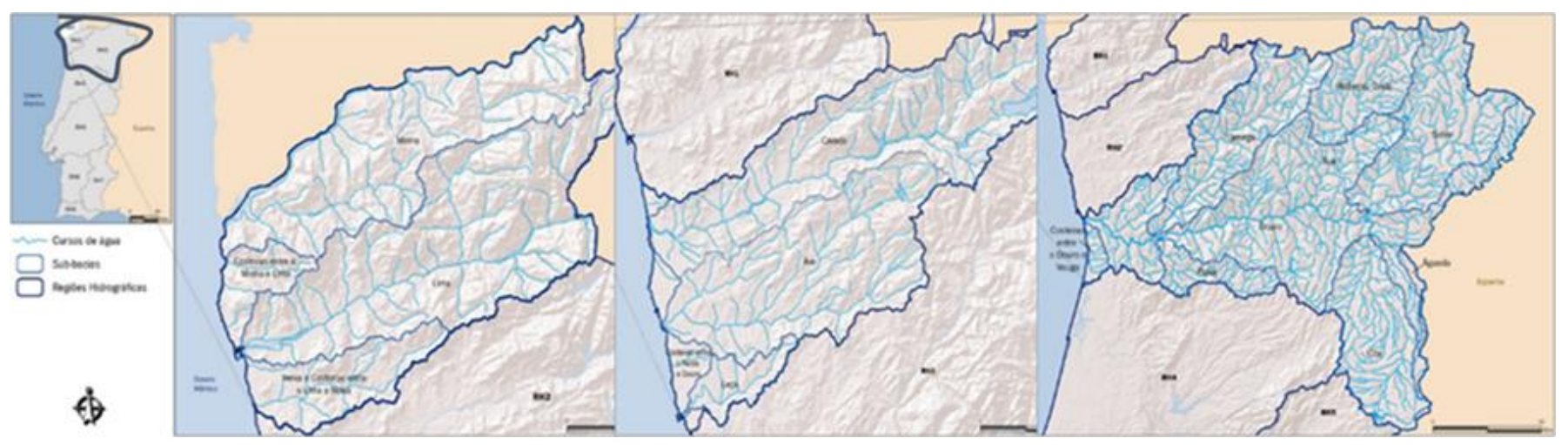

Fonte: IGEOE.

O que pretendemos apresentar são temas com particular interesse do ponto de vista da geografia física para o conhecimento das bacias hidrográfica do norte de Portugal e da evolução das caraterísticas morfométricas dos seus cursos de água.

\section{Desenvolvimento}

São várias as estruturas físicas associadas à utilização das águas públicas para usos agrícolas e industriais, mas são outro tipo de intervenções que devemos considerar no âmbito deste trabalho. Obras e ações que se podem desenvolver, quer na secção, duma forma transversal, quer no leito e ao longo ou sobre as margens, e por isso, de forma longitu7dinal. As intervenções no DPH podem ser classificadas segundo a natureza dos trabalhos efetuados e da área abrangida (COSTA, 2008, 2012, 2010A; COSTA et al., 2017; WASSON et al., 1998): - trabalhos de manutenção - neste estudo centrados nos trabalhos de limpeza das margens e a extração de inertes e penedos; - ações de regularização - destacamos as intervenções relacionadas com os aproveitamentos hidráulicos (açude, canal de fuga, canal de descarga...) e as retificações da corrente (a construção de muros, a canalização, o alinhamento...); - obras estruturais - obras de dimensão variável como por exemplo a construção de pontes e aquedutos.

A limpeza e a extração de areia originavam milhares de pedidos anualmente (COSTA, 2004a, 2008, 2010a) e incluem-se no âmbito dos trabalhos de manutenção, já que, em algumas situações, estes procedimentos contribuíam para o desassoreamento dos leitos dos cursos de água. Além dos proveitos que a extração de inertes permitia, esta suscitava conflitos que decorriam, na maior parte das vezes, do desconhecimento dos impactes negativos deste tipo de atividade. Existem algumas referências sobre as dúvidas que os trabalhos de extração implicavam na paisagem local e as consequências para as atividades de lazer no início do século passado (COSTA, 2008).

Os guarda-rios tinham competências ao nível da avaliação dos potenciais locais para a extração de inertes. Cabia-lhes a missão de analisar os pedidos e em alguns casos, tornava-se necessária uma visita ao local para aferir in loco das possibilidades de tal atividade. Além das dúvidas decorrentes da falta de informação sobre a capacidade dos cursos de água em disponibilizar quantidades de areia por forma a garantir as

ParaOnde!?, Porto Alegre, v.12 n.2, p.238-251, 2019.http://seer.ufrgs.br/paraonde Edição Especial - III Colóquio de Pesquisadores em Geografia Física Ensino de Geografia 
solicitações, outras questões se levantavam, nomeadamente sobre os impactes desta atividade na estabilidade de determinadas estruturas rodoviárias (COSTA et al., 2017).

Além dos milhares de pedidos para esta atividade, entravam também alguns requerimentos para a extração de penedos, em que a principal finalidade estava associada à melhoria do regime dos cursos de águas, sendo que, na maior parte das situações, a pedra era aproveitada para obras nas margens, principalmente na construção de muros de suporte. A destruição ou o corte de penedos é uma operação que ocorre principalmente nas cabeceiras das bacias e que está, sem dúvida, relacionada com a sua morfologia montanhosa de vertentes abruptas, com grande blocos e bolas graníticas típicos da região norte (COSTA, 2004a, 2008; COSTA et al., 2017).

Os aproveitamentos hidráulicos tornaram-se fundamentais, quer no desenvolvimento das atividades agrícolas, quer no impulso dado aos diferentes tipos de indústrias que recorreram a este tipo de estrutura. As obras relacionadas com os aproveitamentos hidráulicos implicam diferentes tipos de intervenções no canal e na sua geometria (figura 1).

Figura 1 - Planta e corte relativos ao processo para a construção de açude no ribeiro do Ribeirinho (Ruivães, São Gens, Fafe, 1912).

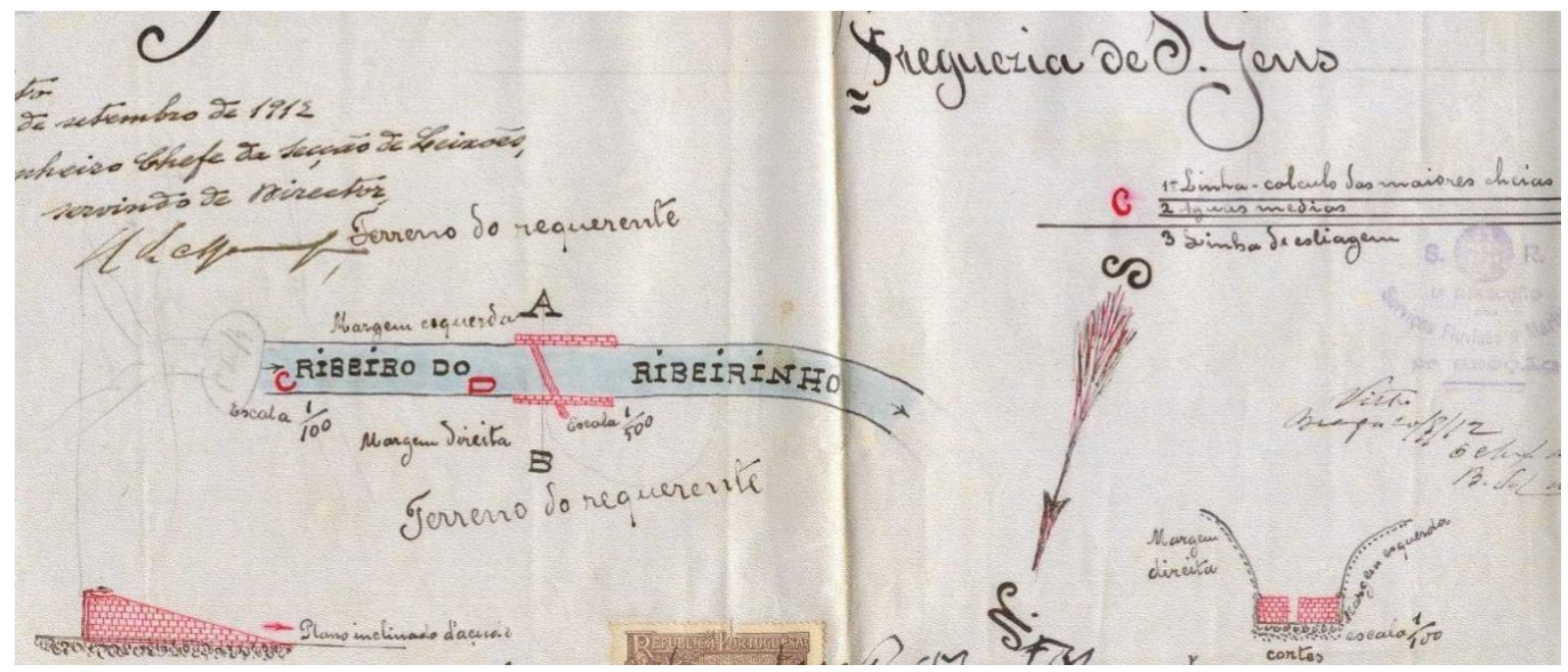
"Obras".

Fonte: Casa de Sarmento, Arquivo da Agência Portuguesa do Ambiente - ARH do Norte, Série

Das diferentes estruturas que constituem um aproveitamento hidráulico, destacamse o açude e a barragem, por serem aqueles que maiores impactes provocam (COSTA et al., 2017). O licenciamento para a construção de açudes e barragens está devidamente definido, quer no regulamento dos Serviços hidráulicos de 1892, quer na Lei de Águas, de 1919. É o artigo 265. o regulamento dos Serviços hidráulicos que estabelece os critérios técnicos a que deve obedecer este tipo de estrutura hidráulica (COSTA, 2008, 2010, 2010b): - a altura pretendida - “ (...) deve ser tal que, em águas médias, o nível da água a montante seja, pelo menos, 0,20 m. mais baixo do que a parte mais baixa dos prédios superiores situados em toda a extensão da represa e $0,10 \mathrm{~m}$. mais baixo do que a parte mais baixa dos aquedutos de esgoto dos terrenos superiores que se acharem na mesma extensão. (...)"; - a existência de descarregador e adufas ou portas em número e com as dimensões calculadas para que, ainda quando a água cresça, o nível da represa fique quanto possível nas condições de não provocar prejuízos; - a construção dum plano

ParaOnde!?, Porto Alegre, v.12 n.2, p.238-251, 2019.http://seer.ufrgs.br/paraonde Edição Especial - III Colóquio de Pesquisadores em Geografia Física Ensino de Geografia 
inclinado com as condições próprias para a passagem do peixe (figura 2).

Figura 2 - Planta e corte relativos ao processo para construir açude no rio Bugio (Regadas, Fafe, 1912).

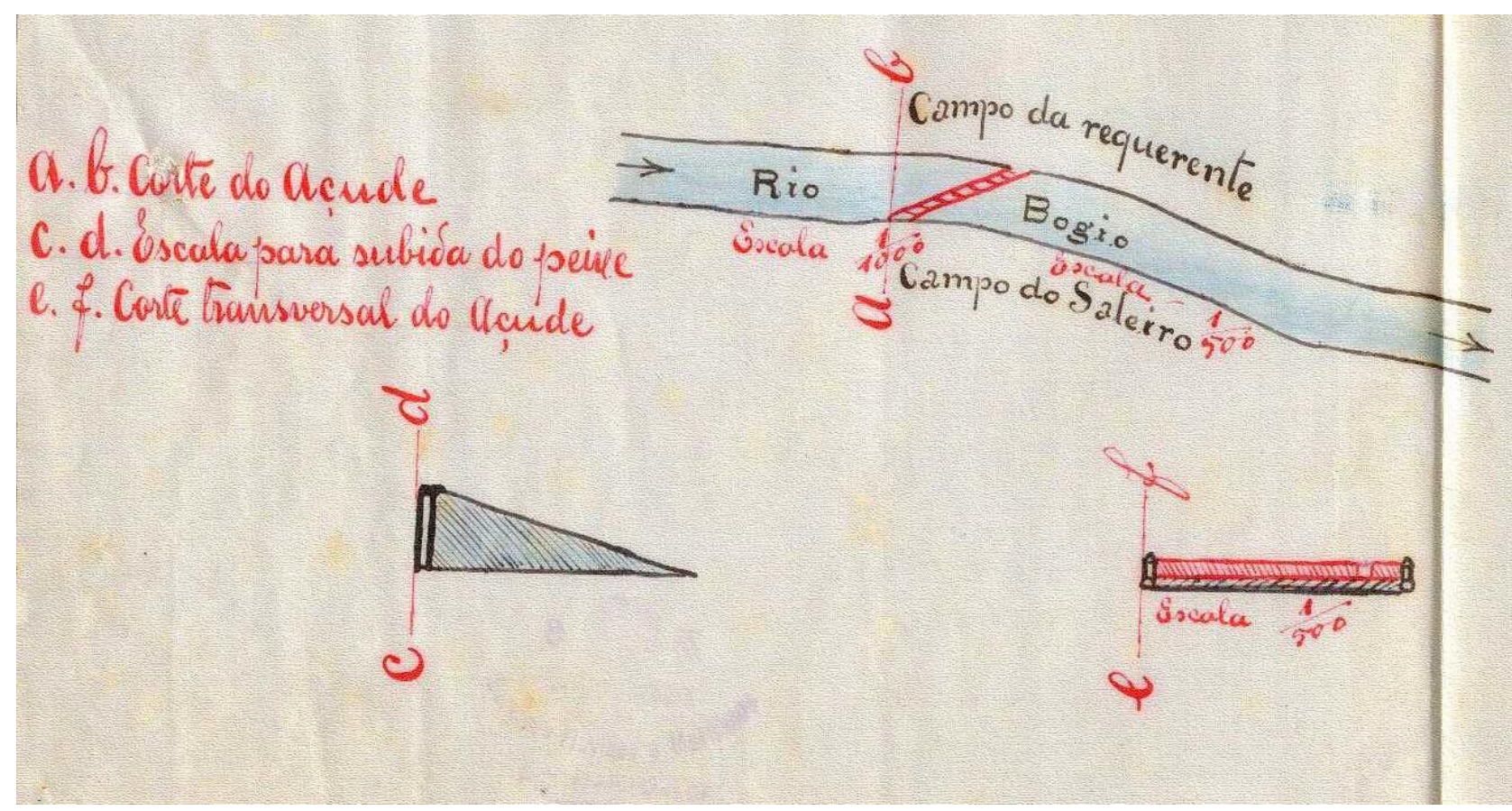
"Obras".

Fonte: Casa de Sarmento, Arquivo da Agência Portuguesa do Ambiente - ARH do Norte, Série

Nos termos do artigo 69. do Regulamento da Lei de Águas e dos artigos $84 . .^{\circ}$ e 85. da própria Lei, a informação prestada devia constar algumas informações de grande interesse do ponto de vista da hidrodinâmica fluvial (COSTA, 2008, 2010b): - a área do aproveitamento, com a designação dos prédios e os nomes dos proprietários nela abrangida; - o local de construção do açude ou barragem, fixando a sua altura ou o processo de derivar as águas. A direção e forma dos canais, levadas ou aquedutos de derivação e devolução à corrente, com individualização dos prédios que tivessem de ser onerados com servidões; - os prejuízos criados ao normal regime das águas ou a qualquer concessão de utilidade pública.

Os açudes começaram desde cedo a fazer parte da paisagem fluvial das bacias do norte de Portugal (COSTA, 2008, 2010b). São de facto numerosos os exemplos que revelam a complexidade que está associada ao aproveitamento dos cursos de água por este tipo de estruturas hidráulicas (COSTA, 2008, 2010, 2010b). Os pedidos relativos a açudes como estruturas fixas cumpram a sua função de reter a água para efetivar a derivação, mas podiam, em alguns casos, constituir obstáculo à vazão dos caudais elevados que ocorrem durante a estação húmida (inverno). Nesta situação, eram frequentes as inundações nos terrenos adjacentes, com prejuízos para os solos, quer pela deposição de substratos menos produtivos, quer pelos efeitos da escorrência concentrada. A maior parte dos prejuízos para os campos ribeirinhos ocorria essencialmente na época das cheias, com a inundação dos campos agrícolas e dos moinhos, que assim, deixavam de laborar normalmente (COSTA, 2008, 2008a). Na maior parte das situações, os proprietários eram obrigados a introduzir alterações na construção dessas estruturas, no sentido de controlar os fluxos da corrente (figura 3).

ParaOnde!?, Porto Alegre, v.12 n.2, p.238-251, 2019.http://seer.ufrgs.br/paraonde Edição Especial - III Colóquio de Pesquisadores em Geografia Física Ensino de Geografia 
Figura 3 - Planta e cortes relativos ao processo para retirar uma comporta do açude do ribeiro de Cuncas (Rego do Moinho, Serzedelo, Póvoa de Lanhoso, 1920.

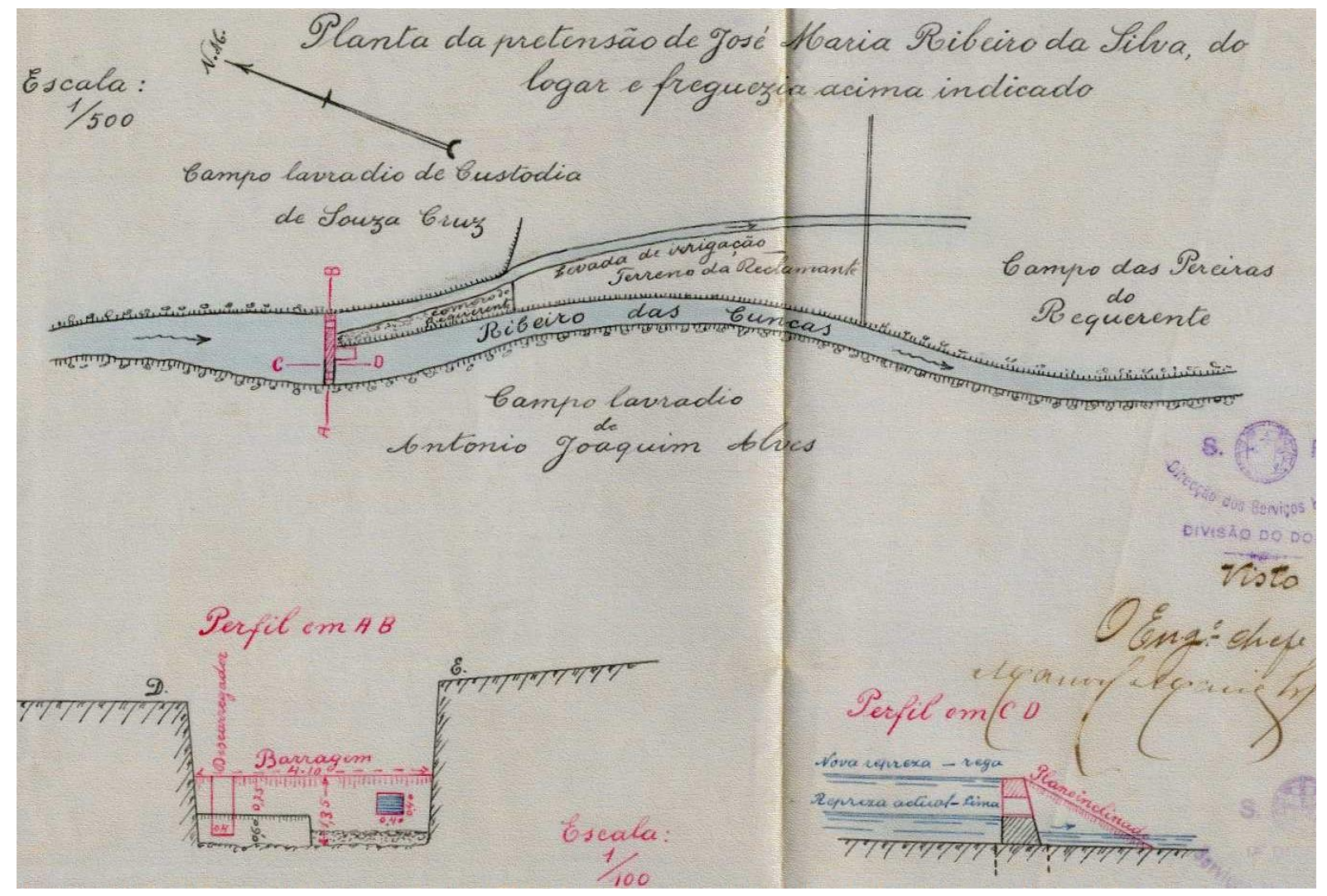
"Obras".

Fonte: Casa de Sarmento, Arquivo da Agência Portuguesa do Ambiente - ARH do Norte, Série

Os pedidos para obras de manutenção dos açudes eram habituais e tinham tendência para aumentar em anos de inundações. Normalmente, este tipo de obras de manutenção dos açudes e barragens não provocavam qualquer tipo de alterações significativas no regime das águas (COSTA et al., 2017). No entanto, existiam outro tipo de ações que introduziam alterações nas características morfométricas, o que originava impactes hidrológicos significativos. A forma mais comum e mais utilizada consistia no aumento da altura do coroamento do açude, situação que podia ser permanente, ou afeta aos períodos de maior secura. Estas alterações morfométricas originavam benefícios significativos, mas também podiam ter impactes negativos, para os proprietários marginais situados a montante desses açudes ou barragens (COSTA et al., 2017). Eram por isso frequentes as reclamações apresentadas, quer por agricultores, quer por outros proprietários das fábricas situadas na proximidade do local de intervenção. A forma de ultrapassar este tipo de problemas ou de evitá-los, passava por um conjunto de intervenções que privilegiavam a colocação de comportas ou descarregadores no açude ou barragem (figura 4)(COSTA, 2008, 2010b).

ParaOnde!?, Porto Alegre, v.12 n.2, p.238-251, 2019.http://seer.ufrgs.br/paraonde Edição Especial - III Colóquio de Pesquisadores em Geografia Física Ensino de Geografia 
Figura 4 - Planta relativa ao processo para abrir cinco comportas num açudelevada no rio Ave (Silvares, Guimarães, 1904).

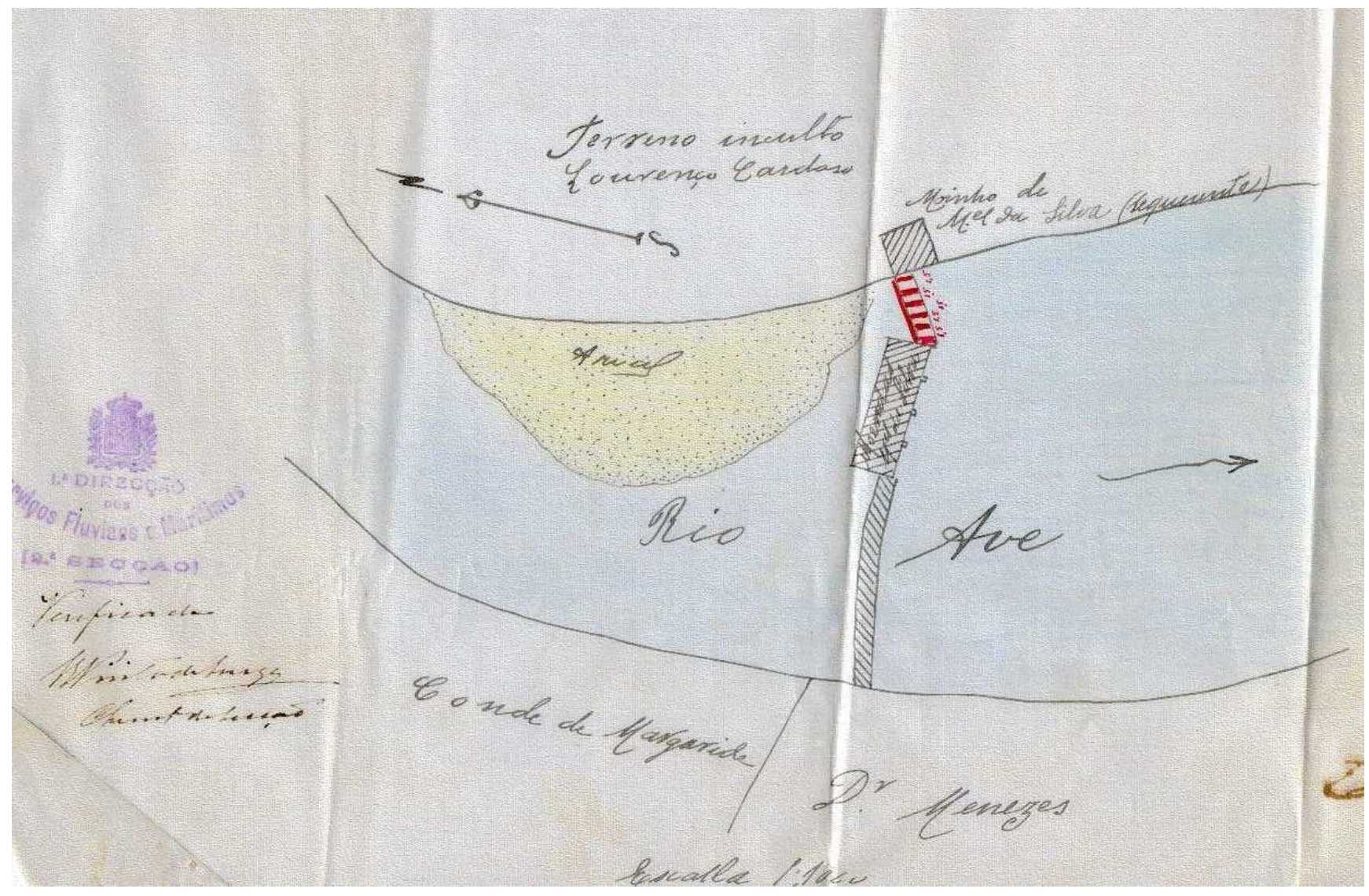
"Obras".

Fonte: Casa de Sarmento, Arquivo da Agência Portuguesa do Ambiente - ARH do Norte, Série

Além dos açudes e das barragens, temos de considerar outras formas de intervenção, que poderemos definir como trabalhos nas margens e, por isso, principalmente perspetivados segundo o perfil longitudinal do curso de água. A partir da análise dos processos do $\mathrm{DPH}$, podemos encontrar um conjunto de conceitos que se enquadram neste tipo de operações: canalização, aquedutamento, regularização, mudança de leito, retificação, e alinhamento dos cursos de água (COSTA et al., 2017). Associados a estas diferentes formas de intervenção, os trabalhos com muros revelam-se fundamentais na relação das margens com o leito dos cursos de água (COSTA, 2004, 2008, 2010a). A necessidade de estabelecer um limite físico com as margens implica, na maior parte dos casos, a construção de muros de suporte, construídos duma forma rudimentar e com recurso a materiais locais (figura 5). 
Figura 5 - Planta e cortes relativos ao processo para reconstruir parte do muro de defesa, na margem esquerda (Sequeiro, Santo Tirso, 1904).

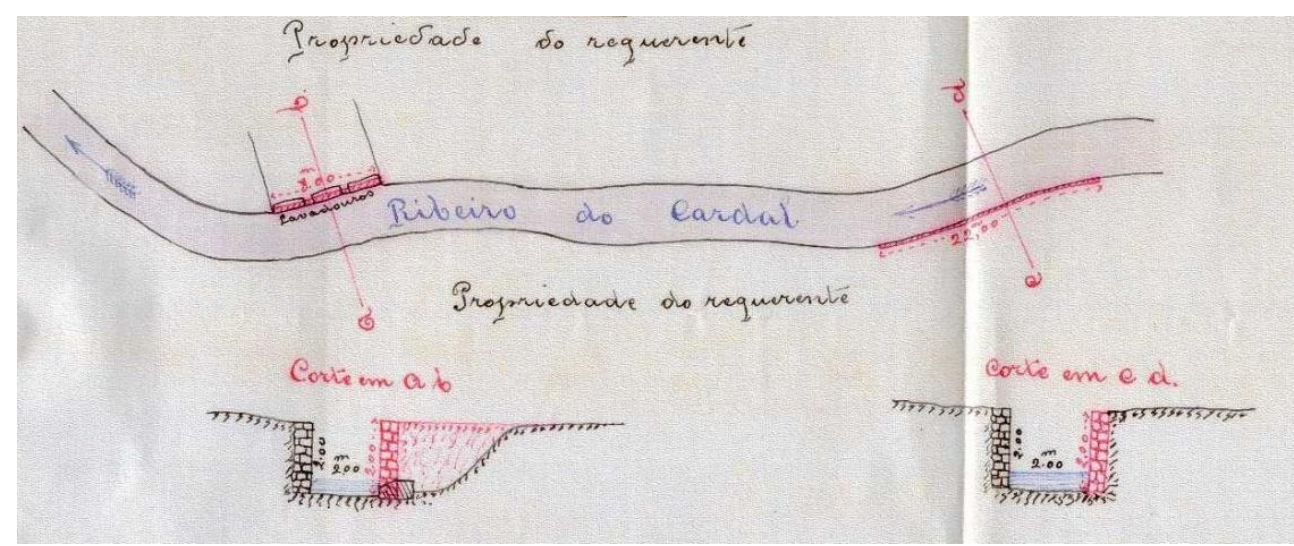
"Obras".

Fonte: Casa de Sarmento, Arquivo da Agência Portuguesa do Ambiente - ARH do Norte, Série

Embora sejam utilizados diferentes termos na apresentação dos requerimentos, as obras com muros destinam-se ao suporte e à defesa das margens, contra as águas das correntes. Os muros de suporte visam, principalmente, evitar o arrastamento de terras para o leito dos rios, diminuindo assim o processo de assoreamento (COSTA et al., 2017).

É no sector inferior das bacias que encontramos o maior número de pedidos para muros de defesa, já que é nesta área que os problemas de escoamento são maiores, quer por motivos de ordem física (características morfológicas e hidrométricas das bacias de drenagem), quer pela maior concentração da população nas áreas ribeirinhas (COSTA et al., 2017). Nas cabeceiras das bacias hidrográficas, o elevado valor de processos associados a muros de suporte deriva essencialmente dos fatores geomorfológicos e da necessidade de suster as terras marginais face à erosão hídrica (COSTA, 2008). Além das funções de suporte e de defesa, a construção de muros está fortemente associada à regularização da maior parte dos cursos de água (figura 6).

Figura 6 - Planta e cortes relativos ao processo para alinhar o rio Pelhe (Pousada, Cruz, Vila Nova de Famalicão, 1918).

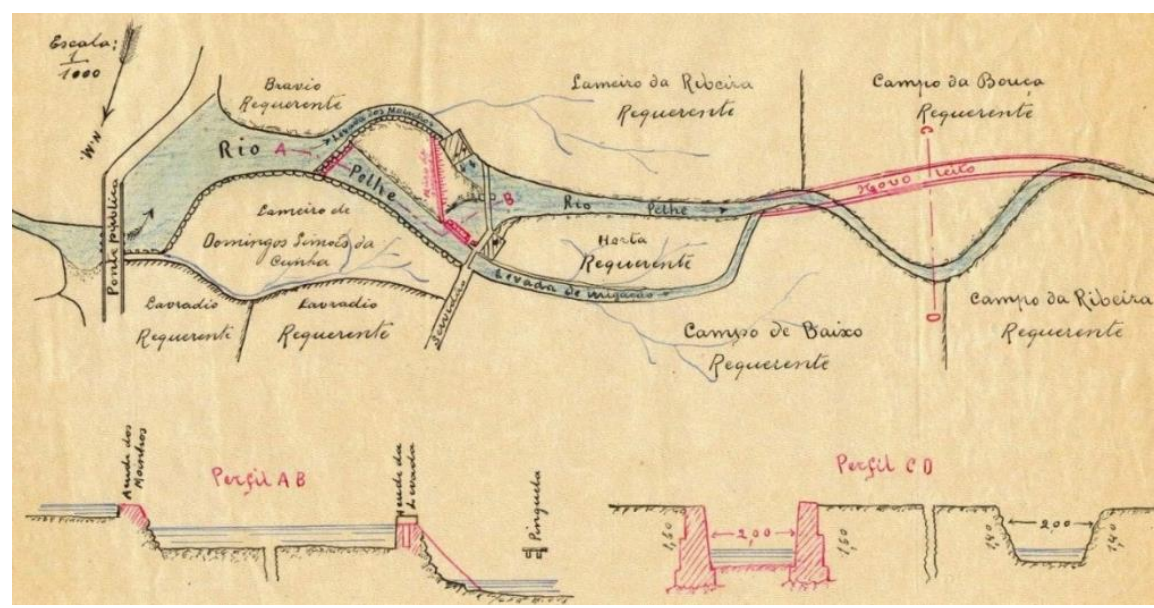
"Obras".

Fonte: Casa de Sarmento, Arquivo da Agência Portuguesa do Ambiente - ARH do Norte, Série

Aqui também convém distinguir os principais tipos de operações - a mudança de

ParaOnde!?, Porto Alegre, v.12 n.2, p.238-251, 2019.http://seer.ufrgs.br/paraonde Edição Especial - III Colóquio de Pesquisadores em Geografia Física Ensino de Geografia 
leitos e a canalização. A maior parte dos trabalhos de mudança de leito eram feitos numa reduzida extensão e passavam por alinhar a corrente com a construção de muros de suporte das novas margens, Além dos benefícios agrícolas que resultavam deste tipo de intervenção, o alinhamento das correntes facilitava, em pequenas curvaturas muito pronunciadas dos cursos de água, a vazão das águas, melhorando, assim, o regime fluvial (figura 7).

Figura 7 - Planta e cortes relativos ao processo para mudar o curso do ribeiro de Micho (Micho, Viatodos, Barcelos, 1918).

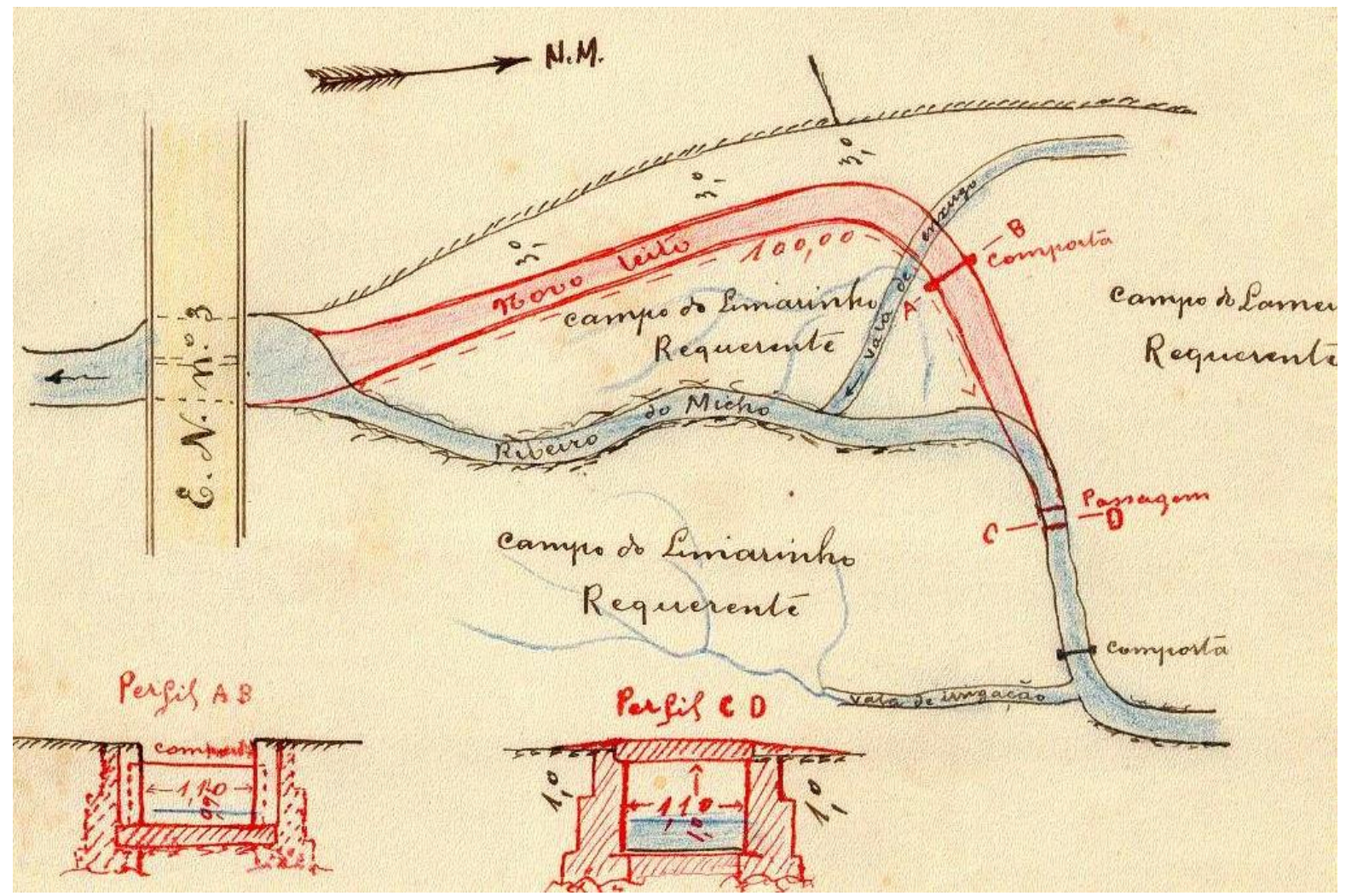
"Obras".

Fonte: Casa de Sarmento, Arquivo da Agência Portuguesa do Ambiente - ARH do Norte, Série

A supressão de curvaturas, de forma a facilitar a vazão e diminuir os riscos de inundação dos campos agrícolas, é também um dos principais fatores neste tipo de intervenções (COSTA et al., 2017). Conforme estava estabelecido, regulamentarmente, os alinhamentos deviam manter as características morfométricas do canal abandonado, isso é, a construção do novo troço devia manter as dimensões do curso suprimido, no que respeita à altura, largura e profundidade. Os novos alinhamentos recorriam, por isso, à construção de muros laterais garantindo também dessa forma, o suporte dos terrenos e a defesa contra as cheias. Duas consequências resultavam diretamente da construção de muros no novo leito: a alteração das margens e o abandono do troço retificado. A mudança de leito obrigava a proceder a ações sobre o troço abandonado. A forma mais simples e mais utilizada, em terrenos de cultivo, consistia na cobertura ou no enchimento do antigo canal (COSTA et al., 2017).

Além da mudança de leito em propriedades agrícolas, esta operação surge relacionada com as necessidades decorrentes da expansão urbana e, principalmente, com os efeitos da implantação industrial. Muitas fábricas, durante a sua instalação inicial

ParaOnde!?, Porto Alegre, v.12 n.2, p.238-251, 2019.http://seer.ufrgs.br/paraonde Edição Especial - III Colóquio de Pesquisadores em Geografia Física Ensino de Geografia 
ou nas fases de ampliação, tinham, também, a necessidade de procederem à mudança dos cursos de água que atravessavam a sua propriedade industrial. É neste contexto que a cobertura se tornou mais frequente, já que por um lado, tornava possível a implantação/ocupação urbana e industrial sobre os cursos de água, e por outro, resolvia alguns problemas de saúde pública, de origem hídrica (figura 8).

Figura 8 - Planta e cortes relativos ao processo para cobrir o ribeiro de Passos (rua Pereira Caldas, Caldas de Vizela (São Miguel), Guimarães, 1919).

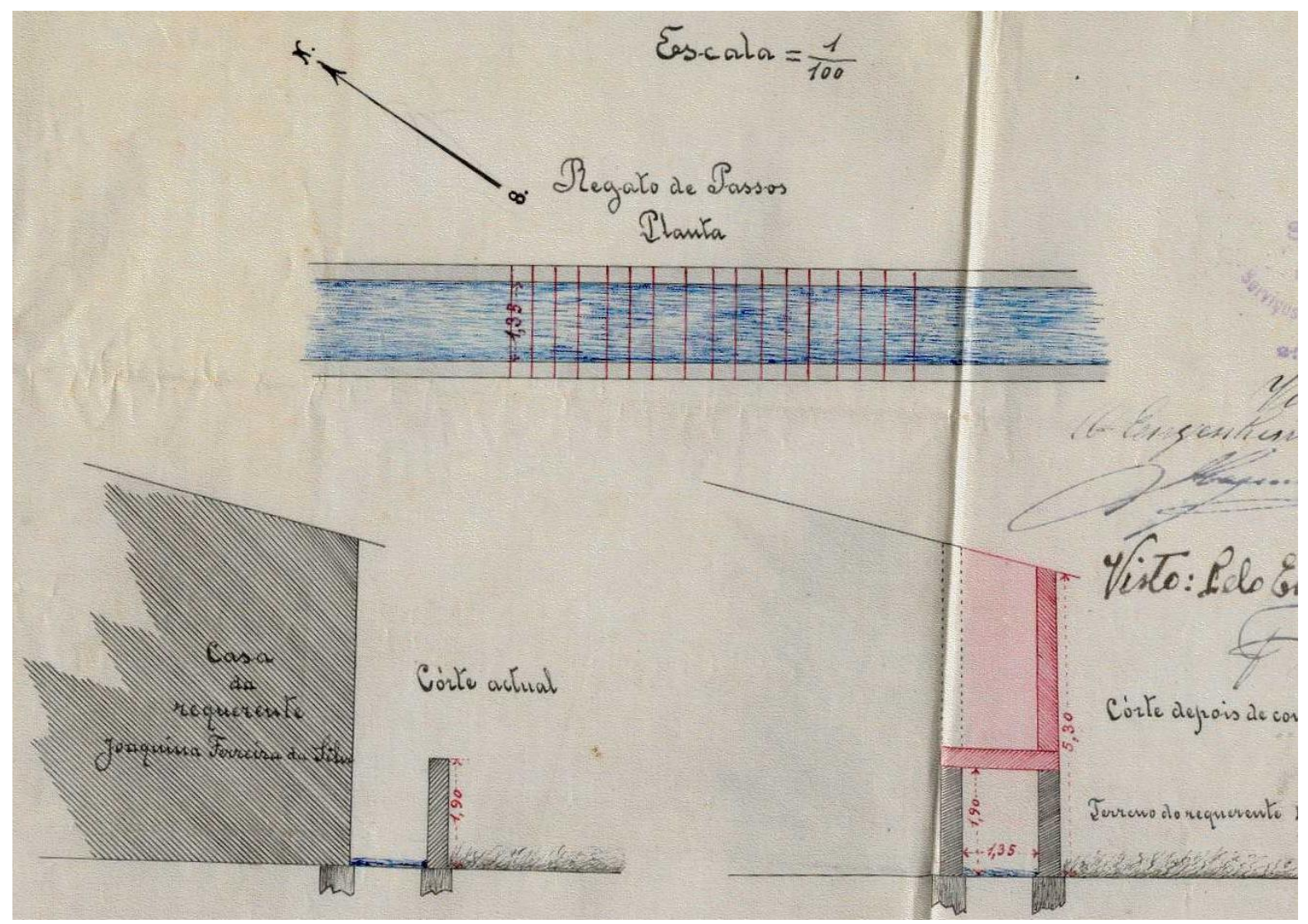
"Obras".

Fonte: Casa de Sarmento, Arquivo da Agência Portuguesa do Ambiente - ARH do Norte, Série

Com vários impactes do ponto de vista hidrológico e ambiental, estas intervenções eram, maioritariamente, de implantação local e à uma escala reduzida. Estas situações eram frequentes nos logradouros urbanos e industriais e assumiam diferentes tipos de trabalhos: - o alargamento; - o aquedutamento; - a canalização; - a regularização das margens e do leito; e a retificação (COSTA et al., 2017). De forma a identificar os possíveis efeitos decorrentes destas obras de regularização, nomeadamente a canalização de leitos e assim poder tomar decisões mais sustentadas no que respeita ao licenciamento, a Direção Geral dos Serviços Hidráulicos emite, em 1968, uma circular em que aponta os seguintes elementos necessários à apreciação dos respetivos projetos (COSTA, 2008): - a delimitação da bacia e a respetiva área; - a avaliação do caudal de cheia a prever;- o perfil longitudinal do leito da corrente, num mínimo de 300 metros para montante e para jusante; em obras importantes ou em leitos com pequena inclinação, deveria abranger uma maior extensão, até $1000 \mathrm{~m}$; - e os perfis transversais do leito e na

ParaOnde!?, Porto Alegre, v.12 n.2, p.238-251, 2019.http://seer.ufrgs.br/paraonde Edição Especial - III Colóquio de Pesquisadores em Geografia Física Ensino de Geografia 
extensão relativa ao perfil longitudinal traçado. Estes perfis poderiam ser levantados de 100 em 100 metros, em larguras mínimo de 5 metros em cada margem. Além deste conjunto de características técnicas, estes projetos deviam também incluir elementos informativos sobre os níveis das cheias conhecidas no local, os perigos e inconvenientes resultantes destas cheias, ou dos eventuais regolfos de elevação, provocados pelas obras projetadas. Os estudos hidráulicos realizados permitiram compreender melhor a dinâmica fluvial de algumas pequenas bacias de drenagem e vieram fundamentar as decisões tomadas relativamente aos pedidos de licenciamento de canalização (COSTA et al., 2017).

Entre as diferentes formas de intervenção sobre o leito e sobre as margens temos também de considerar a construção de infraestruturas, entre as quais destacamos as pontes e os aquedutos. A construção de pilares ou vãos nas pontes, implicava frequentemente com a secção de vazão e por isso tinha implicações no regime fluvial (COSTA, 2004, 2008). Em período de cheias, eram, por isso, frequentes os episódios que punham em causa a estabilidade da estrutura das pontes. A debilidade das estruturas e a má conceção, em termos de vazão, de muitas pontes, foram responsáveis por algumas situações de queda e destruição. Por forma a obviar este tipo de problemas, tornava-se essencial o reforço das estruturas existentes e muitos pedido foram feitos nesse sentido (figura 9)(COSTA et al., 2017).

Figura 9 - Planta e cortes relativos ao processo para modificar antiga ponte sobre o rio Bugio (Valsa, Regadas, Fafe, 1920).

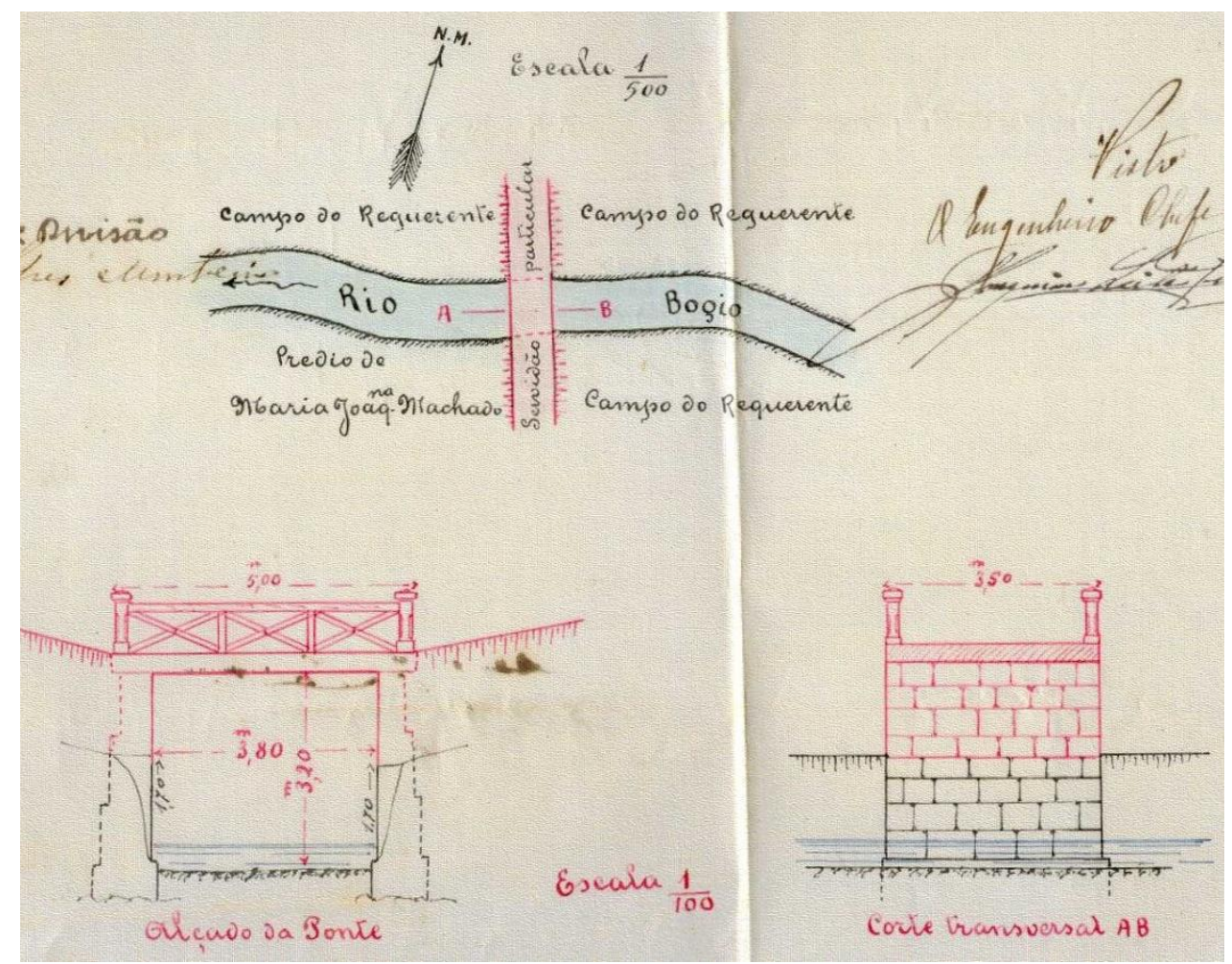
"Obras".

Fonte: Casa de Sarmento, Arquivo da Agência Portuguesa do Ambiente - ARH do Norte, Série

A preocupação com as cheias e seus impactes na estrutura das pontes obrigou, em muitos projetos, a incluir os cálculos relativos à avaliação do caudal de cheia a prever. Até 1968, os projetos sobre pontes não incluíam de forma obrigatória o estudo hidráulico,

ParaOnde!?, Porto Alegre, v.12 n.2, p.238-251, 2019.http://seer.ufrgs.br/paraonde Edição Especial - III Colóquio de Pesquisadores em Geografia Física Ensino de Geografia 


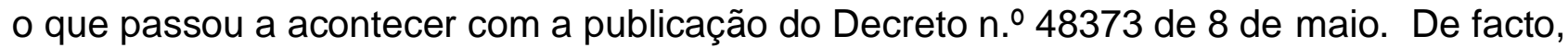
nessa altura são realizados vários estudos hidráulicos sobre as pontes com interferência direta no regime das águas públicas. Estes estudos deram um importante contributo no conhecimento dos sistemas hidrológicos a nível local, já que visavam apontar as soluções mais adequadas do ponto de vista hidráulico: mesmo aplicando diferentes metodologias na sua aplicação, os estudos hidráulicos mostram que as decisões tomadas implicavam a realização de obras de segurança, por forma a minimizar os riscos associados a episódios hidrológicos extremos (COSTA et al., 2017).

Duma forma geral, os diferentes trabalhos e obras efetuados no DPH referem-se a obras de pequena dimensão e, por isso, de impactes à escala local. Não podemos, no entanto, deixar de referir que a conjugação do acumular no elevado número de obras com os diferentes tipos de intervenções em causa, terá, por certo, tido consequências nefastas, que ainda hoje se fazem sentir, bem como, explicarão muitos dos problemas de natureza hidrológica e hidráulica que afetam muitos cursos de água das bacias do norte de Portugal.

\section{Considerações finais}

A riqueza documental do arquivo da APA e suas potencialidades no âmbito da investigação permitem estudos diversificados, quer no domínio da Geografia, das ciências históricas, do património, do planeamento e também em alguns campos da hidráulica e hidrologia ligadas à gestão do território das áreas ribeirinhas. O acervo histórico da APA é um dos mais ricos arquivos locais do país, reunindo um conjunto de milhares de documentos que vão do século XIX à atualidade, constituindo um repositório documental com características impares e um testemunho da identidade, memória e história dos cursos de água da região norte (COSTA e CORDEIRO, 2012a). Dar a conhecer este espólio vai permitir disponibilizar e tratar informação geográfica fundamental no conhecimento das bacias hidrográficas e sua gestão. $O$ arquivo tem imensas potencialidades no âmbito da investigação geográfica pelo que também nos cabe divulgar este importante património na defesa de uma memória comum que urge preservar (COSTA, 2012, COSTA e CORDEIRO, 2012, 2012a, 2015, COSTA et al, 2015).

\section{Referências}

CAMPELO, A. Das hidráulicas aos recursos hídricos: história, sociedade e saber. Edições ARH do Norte, I.P. Porto, 2011, 139 p.

CARVALHO R. Historiador e as Fontes Históricas. Consultado em 17 de junho de 2019. http://www.webartigos.com/artigos/o-historiador-e-as-fontes-historicas/22598/

COSTA, F. S., VIEIRA, A. A. B., BENTO-GONÇALVES, A. J. Understandingthepastofrivers: readingthehistoryofriversfromdocumentsandmaps. Chapter 18. In: Basics of open channelhydraulics, river training and fluvial geomorphology, editors: Artur Radecki-Pawlik, StefanoPagliaraand Jan Hradecky. Science Publishers, Taylor \& Francis Group, 2017,p. 346-371.

ParaOnde!?, Porto Alegre, v.12 n.2, p.238-251, 2019.http://seer.ufrgs.br/paraonde Edição Especial - III Colóquio de Pesquisadores em Geografia Física Ensino de Geografia 
COSTA, F. S. O arquivo da Administração da Região Hidrográfica do Norte. Roteiro metodológico. In: Manuela Martins, Isabel Vaz de Freitas, Maria Isabel DelValValdivieso (Coords.). Caminhos da água. Paisagens e usos na longa duração., CITCEM-Centro de Investigação Transdisciplinar “Cultura, Espaço e Memória”, Braga, 2012, p. 267-293.

COSTA, F. S. Licenciamento em águas públicas e cartografia - O caso do rio Ave no início do século XX. In: Norberto Santos e Lúcio Cunha, Trunfos de uma geografia ativa, Imprensa da Universidade de Coimbra, Coimbra, 2011, p. 593-602.

COSTA, F. S. Águas públicas e sua utilização no concelho de Fafe - Um contributo do ponto de vista histórico-geográfico. Câmara Municipal de Fafe, Fafe, 2010, 144 p.

COSTA, F. S. Domínio Público Hídrico na bacia hidrográfica do rio Ave - uma breve perspectiva histórica. $1^{\circ}$ Seminário sobre Gestão de Bacias Hidrográficas "As Regiões do Norte e as Perspectivas Futuras de Gestão", Associação Portuguesa dos Recursos Hídricos - Núcleo Regional do Norte, Associação Portuguesa dos Recursos Hídricos Núcleo Regional do Norte, 2010a, p. 111-116.

COSTA, F. S.Geopatrimónio ligado à água. O caso do património industrial na bacia hidrográfica do rio Ave. Atas do VI Seminário Latino-Americano, II Seminário IberoAmericano de Geografia Física "Sustentabilidade da Gaia: ambiente, ordenamento e desenvolvimento", CEGOT, Universidade de Coimbra,2010b 12 p.

COSTA, F. S. A Gestão das Águas Públicas: o caso da bacia hidrográfica do rio Ave no período 1902-1973. Dissertação de doutoramento em Geografia, Universidade do Minho, Braga, 2008, 857 p.

COSTA, F. S. O papel dos moinhos no aproveitamento hidráulico das águas públicas do rio Ave - Um contributo na perspectiva do património ligado à água. Atas do VII Colóquio Ibérico de Estudos Rurais "Inovação e Território", 23 a 25 de outubro, Escola Superior Agrária de Coimbra (ESAC), Coimbra, 2008a, 23 p.

COSTA, F. S. As águas públicas na bacia do Ave: umaperspectiva do ordenamento do território no início do século XX. Atas do 7º Congresso da Água, Lisboa, 2004, 14 p.

COSTA, F. S., CORDEIRO, J. M. L. Archiv-AVE "Património documental da bacia do Ave". In: Costa, F. S., Cordeiro, J. M. L., Vieira, A. A. B., Silva, C. C. S. (Orgs,), UMinhoDGEO, Departamento de Geografia da Universidade do Minho, Guimarães, 2015, $52 \mathrm{p}$.

COSTA, F. S., CORDEIRO, J. M. L. O Sistema de Informação Arquivística da Agência Portuguesa do Ambiente (SIAPA): um projeto para recuperar a memória dos Serviços Hidráulicos. In:Membiela, P., Casado, N. C., Cebreiros, M. A. (Eds.), Panorâmica interdisciplinar sobre el agua. Educación Editora, Ourense, Espanha,2015a, p. $63-67$

COSTA, F. S., CORDEIRO, J. M. L. O arquivo da Administração da Região do Norte. Um contributo na abordagem histórico-geográfica do Domínio Público Hídrico. Atasdo

ParaOnde!?, Porto Alegre, v.12 n.2, p.238-251, 2019.http://seer.ufrgs.br/paraonde Edição Especial - III Colóquio de Pesquisadores em Geografia Física Ensino de Geografia 
$11^{\circ}$ Congresso da água "Valorizar a água num contexto de incerteza", Porto, 6 a 9 de fevereiro de 2012, Associação Portuguesa de Recursos Hídricos, 2012, 10 p.

COSTA, F. S., CORDEIRO, J. M. L. O CEDOCAVE - Centro de Documentação sobre Água no Cávado e Ave: um projeto para preservar a memória e divulgar o património e cultura da água. Atas das VIII Jornadas de Geografia e Planeamento "Cidades, criatividade(s) e sustentabilidade(s)", Guimarães, 2012a, p. 21-28.

CORDEIRO, J. M. L. Indústria e energia na Bacia do Ave: [1845-1959], Cadernos do Noroeste, Série História, №1, 2001, Braga, p. 57-174.

COSTA, F. S., CORDEIRO, J. M. L., VIEIRA, A. A. B., SILVA, C. C. S. Archiv-Ave: um projeto para conservar e divulgar o património documental do rio Ave. In; António Vieira \& Francisco Costa (Orgs,), II Simpósio de Pesquisa em Geografia, Universidade do Minho - Universidade Federal de Santa Maria, Guimarães, Coleção Atas, 4, UMinhoDGEO, Guimarães, 2015, p.50- 63.

KETELAAR, E. Time future contained in time past. Archivalscience in the $21 \mathrm{st}$ century. JournaloftheJapanSociety for ArchivalScience 1, 2004, p. 20-35.

MILLIGAN, J.D. TheTreatmentofanHistoricalSource. HistoryandTheory 2, 1979, p. 177-196.

PATO, J. O Valor da Água como Bem Público. Tese de doutoramento em Ciências Sociais, Instituto de Ciências Sociais da Universidade de Lisboa, 2008.

PRADO, E. L. A importância das fontes documentais para a pesquisa em História da Educação. InterMeio: revista do Programa de Pós-Graduação em Educação, Campo Grande, MS, v.16, n.31, jan./jun, 2010, p.124-133.

WASSON, J-G. MALAVOI, J. R., MARIDET; L., SOUCHON, Y., PAULIN, L.Impactsécologiques de la chenalisationdesrivières. ÉtudesGestiondesmilieuxaquatiques, Cemagref Ed., Lyon,1998, 158 p. 